\title{
Marco geológico y tectónico de la Isla del Coco y la región marítima circunvecina, Costa Rica
}

\author{
Wilfredo Rojas ${ }^{1,4}$ \& Guillermo E. Alvarado $2,3,4$ \\ 1. Escuela Centroamericana de Geología, Universidad de Costa Rica, San Pedro Montes de Oca, San José, Costa Rica; \\ wrojas@geologos.or.cr \\ 2. Área de Amenazas y Auscultación Sismológica y Volcánica, Instituto Costarricense de Electricidad (ICE), Apdo. \\ 10032-1000, Costa Rica, galvaradoi@ice.go.cr \\ 3. Centro de Investigaciones Geológicas, Universidad de Costa Rica. \\ 4. Red Sismológica Nacional (RSN: UCR-ICE).
}

Recibido 07-III-2012. C Corregido 09-VIII-2012. Aceptado 25-IX-2012.

\begin{abstract}
Geological and geotectonic framework of Isla del Coco and the marine zone off the central Pacific coast of Costa Rica. The Isla del Coco (also known as Cocos Island), in the Eastern Pacific Ocean, has a rough topography, an area of $24 \mathrm{~km}^{2}$, and is the only sub-aerial topographic height of the summit of a volcano located in the margin of the Cordillera Volcánica del Coco (also known as Cocos Ridge). The Cocos Ridge is a well defined linear bathymetric height, issued from the active volcanism of the Galápagos hotspot during the last 15 million years (Ma); it is the largest geographic feature of Costa Rica, as a volcanic range of 780km long in its territorial seawaters. Isla del Coco is part of a submarine shield volcano of complex evolution, which erupted several times above sea level during the Lower Pleistocene (2.2-1.5Ma). The island and other seamounts are the result from a mantle thermal anomaly that erupted through volcano-tectonic fissures in the oceanic crust. The rocks consist mainly of alkali basaltic lava flows (aa, pahoehoe, blocky lavas) and dikes, minor trachyte lava flows, volcanic domes and dikes, with subordinate pyroclastic and epivolcanic rocks. Colluvial, soils and local littoral deposits such as sand and gravel beaches are also present. The island has a juvenile erosive stadium, but their submarine erosive arcs and platforms $(90-110 \mathrm{~m}$ and $183 \mathrm{~m}$ depth) are probably the result of the erosion occurred during last two glacial maxima, besides slow subsidence events of the island due the thermal cooling of the volcanic shield and its oceanic crust. The most important current external geodynamic hazards are landslides, tsunamis and rare seismic events, $\mathrm{M}_{\mathrm{w}} \leq 5.8$ in a $300 \mathrm{~km}$ radio associated to N-S right lateral strike slip faults. However, the limited seismic data available, and geomorphological alignments, indicates that there is some seismic activity related to local faults oriented N-S, ENE and in a lesser extend NW trend. Seismicity and rainfall have triggered landslides; liquefaction is restricted to Chatham and Wafer bays' beaches. Moderate historical and prehistorical tsunamis were related to regional seismic events. The relative young age of Isla del Coco makes it an interesting place to study the evolution and migration of species, and their genetic features. More detailed studies related to tephrostratigraphy, neotectonics, marine geomorphology, evolution of seamounts, lava flow morphology, and submarine hydrothermal activity, are still necessary to understand the expression of internal geodynamic processes in this region. Citation: Rojas, W. \& G.E. Alvarado. 2012. Marco geológico y tectónico de la Isla del Coco y la región marítima circunvecina, Costa Rica. Rev. Biol. Trop. 60 (Suppl. 3): 15-32. Epub 2012 Dec 01.
\end{abstract}

Key words: Costa Rica, Isla del Coco, Cocos Island, Cocos Ridge, geology, tsunamis, seismo-tectonics, geodynamic hazards.

La Isla del Coco se ubica 496km al suroeste de Cabo Blanco (Península de Nicoya), el punto costero costarricense más cercano. El área de estudio se localiza dentro de la zona marítima del lado del Pacífico de Costa Rica en las coordenadas $5.540^{\circ} \mathrm{N}$ y $87.057^{\circ} \mathrm{W}$.
Pese a que la Isla del Coco es conocida por sus leyendas de tesoros allí resguardados (Weston 1992), su verdadero valor radica en la riqueza de sus especies animales y vegetales. Además, es el único afloramiento subaéreo de la Cordillera Volcánica del Coco, lo 
cual implica importantes repercusiones para el endemismo y evolución de las especies, y un punto atracción para la investigación marina (Dalrymple \& Cox 1968, Cortés 2008). Así mismo, en este sitio fue registrada la presencia, por primera vez, del mineral anortosa en nuestro país (Alvarado 1984). Esta es la cordillera de mayor longitud de Costa Rica y de América Central (Alvarado 2000), y constituye la única isla oceánica costarricense desde el punto de vista estricto (Cortés 2007), además de ser un punto geográfico excelente para el funcionamiento de una estación sismográfica, que suministre datos que mejoran el procesamiento, ubicación e interpretación de los temblores Centroamericanos (Rojas 2000). Finalmente, pero de vital importancia, resulta la de ampliar significativamente el área de Costa Rica, en donde las primeras 12 millas marítimas (1 milla marítima $=1,8 \mathrm{~km}$ ) corresponden con la denominada zona marítima o mar territorial (extensión aproximada de unos $14000 \mathrm{~km}^{2}$ ) y el resto es mar patrimonial o la Zona Económica Exclusiva (ZEE), para un total aproximado de unos $548000 \mathrm{~km}^{2}$ de extensión marina. Estos datos son preliminares y no oficiales, dado que todavía requieren definirse geopolíticamente por parte de los gobiernos vecinos y las Naciones Unidas, pero evidentemente posee importantes repercusiones para la economía pesquera, los recursos minerales del fondo oceánico, investigaciones científicas y estrategia nacional.

Aunque la Isla del Coco es considerada un laboratorio biológico natural, poco se menciona sobre su constitución geológica, en particular en la literatura en español. La mayoría de las menciones geológicas son antiguas (Dalrymple \& Cox 1968, Malavassi 1982, Bellon et al. 1983, Alvarado 1984, Castillo et al. 1988), o sus consideraciones geológicas son incompletas, complejas y englobadas dentro de la tectónica regional (Meschede et al. 2000, Werner et al. 2003, Harpp et al. 2005, O'Connor et al. 2007), por lo que no fácilmente accesibles para los no especialistas en el tema. Tampoco existe una síntesis sobre los aspectos geológicos relevantes, a los que los biólogos y otros científicos puedan tener acceso y que les sea útil para sus fines. De igual modo, se conoce muy poco sobre las amenazas naturales asociadas a la geodinámica externa e interna en este territorio insular.

Por ello, el objetivo del presente trabajo es el ofrecer un esbozo sobre el marco geológico de la Isla del Coco y de la Cordillera Volcánica del Coco, sus particularidades geológicas, evolución, aspectos geomorfológicos y sismológicos sobresalientes, incluyendo las amenazas naturales geodinámicas que puedan afectar en algún grado a este territorio insular y oceánico. Este no pretende ser un tratado geológico exhaustivo, para lo cual se remite al lector a la literatura especializada citada.

\section{METODOLOGÍA, ALCANCES Y LIMITACIONES}

Se consultó gran parte de la literatura geológica y otras obras afines, y se realizaron cuatro visitas cortas a la Isla del Coco por parte del primer autor y una por parte del co-autor, con poca disponibilidad de tiempo en todas ellas, situación que incide en no poder profundizar más en los aspectos geológicos (particularmente vulcanológicos y tectónicos). Pese a ello, se recopiló información geológica básica, y se instalaron equipos sismológicos con transmisión en internet hacia el laboratorio Central de la Red Sismológica Nacional (RSN), con sede en la Escuela Centroamericana de Geología de la Universidad de Costa Rica. La estación sismológica de banda ancha, del tipo Guralp, instalada en la Isla del Coco a partir del 2000, ha aportado información novedosa sobre la sismicidad, la tectónica local y los tsunamis que han afectado a la Isla. También se contó con modelos tridimensionales de la morfología submarina de la Isla del Coco, amablemente aportados por el Dr. Omar G. Lizano, que fueron geológicamente interpretados. Además, se tuvo a disposición de fotografías del sumergible. Sin embargo, claramente se requieren de estudios vulcanólogicos y tectónicos de detalle, de la morfología del fondo oceánico para determinar paleo-deslizamientos, así como un estudio de 
la influencia de los pasados periodos glaciares e interglaciares, además de tener una cuantificación por medio de una estaciones geodésica de precisión de si existe subsidencia en la isla.

\section{CONTEXTO GEOTECTÓNICO}

La Isla del Coco forma parte de la Cordillera Volcánica del Coco, la cual consiste de una cadena de montes y volcanes submarinos que se extiende por espacio de $1200 \mathrm{~km}$ en forma más o menos continua desde las Islas Galápagos (Ecuador) hasta el frente de la costa Pacífica, en el sector sureste de Costa Rica, entre Punta Burica y Quepos (Fig. 1), justo en la denominada Fosa Mesoamericana, donde termina dicho rasgo morfotectónico.

Dentro de los primeros estudios batimétricos acerca del fondo oceánico, pueden mencionarse los de Hey (1977) y Hey et al. (1977), quienes los asocian con dentro de la Placa del Coco y que debieron ser originadas cerca del punto caliente de las Galápagos. Esta última es una anomalía termo-volcánica del manto terrestre, que ha creado volcanes submarinos desde por lo menos unos 15Ma (millones de años), y que se localiza a su vez muy cerca de la dorsal de las Galápagos (Hey 1977). Los volcanes que conforman dicha cordillera están siendo transportados y subducidos bajo el territorio costarricense actual, a lo largo de varios millones de años, mediante el proceso aún activo de la mediante la teoría de la tectónica de placas.

Los estudios vulcanológicos recientes evidencian que los volcanes más antiguos corresponden con la sierra submarina de Fisher, cuyas edades son de 19 y 30Ma (i.e. los cerros Fisher), mientras que los más recientes, situados y relacionados directamente con en la Cordillera Volcánica del Coco frente a nuestras costas, poseen edades entre 13 y $14.5 \mathrm{Ma}$ (Werner et al. 2003). Debido a que en el fondo oceánico la erosión es casi nula, gran parte de la morfología de estos conos volcánicos ha quedado prácticamente congelada en el tiempo, y algunos de ellos exhiben hasta su cráter perfectamente conservado (Alvarado 2000).
Las dataciones radiométricas publicadas de la Cordillera Volcánica del Coco se distribuyen en 7 grupos: a) $14.4-10.0 \mathrm{Ma}$, b) $8.8-8.3 \mathrm{Ma}$, c) $5.7-5.2 \mathrm{Ma}$, d) $4.2-3.4 \mathrm{Ma}$, e) $2.2-1.9 \mathrm{Ma}$, f) $1.5 \mathrm{Ma} \mathrm{y} \mathrm{g)} 0.6 \mathrm{Ma}$, lo cual evidencia que la actividad volcánica submarina no ha sido continua, sino más bien episódica (Fig. 2). Las lavas de la Cordillera poseen una composición que las hace clasificarse como basaltos y andesitas basálticas toleíticas. Las lavas más antiguas, no relacionadas con la Cordillera del Coco, corresponden con basaltos alcalinos provenientes de la Serranía Fisher ( 30 y 19.2Ma) (Dalrymple \& Cox 1968, Bellon et al. 1983, Werner et al. 2003, Harpp et al. 2005, O'Connor et al. 2007, Alvarado \& Gans 2012).

Como ya se anotó, la Isla del Coco está ubicada aproximadamente hacia la parte central de la Cordillera Volcánica del Coco, cuyo nombre proviene por estar la Isla del Coco emplazada sobre ella (nombre que también adquiere la placa) y por ser el único afloramiento de dicha cordillera sobre el nivel del mar. Debido a la ausencia aparente de sismicidad, se le había asignado el nombre de dorsal asísmica (Aseismic Cocos Ridge) por los especialistas en geotectónica que la habían estudiado hasta la fecha, pero como se verá más adelante dentro del presente estudio, sí se ha encontrado un moderado a bajo grado de actividad sísmica. Entonces, por no ser una dorsal medio oceánica (rift or mid-ocean ridge) propiamente dicha, desde el punto de vista geográfico y vulcanológico, es mejor llamarla Cordillera Volcánica del Coco (Coco Volcanic Range). Así mismo, esta es la cordillera costarricense más extensa (Alvarado 2000), con unos $780 \mathrm{~km}$ de longitud dentro de sus aguas territoriales (Fig. 1).

Según el modelo de Hey et al. (1977), el basamento de la Isla del Coco, en la placa del mismo nombre, se encuentra ubicada entre las isocronas de 10 y $15 \mathrm{Ma}$ (i.e. principalmente Mioceno Medio). Sin embargo, las dataciones radiométricas aportan, para la Isla propiamente dicha, edades de 2.2 a $1.5 \mathrm{Ma}$, así como para los volcanes submarinos circundantes entre 1.3 y $0.6 \mathrm{Ma}$, las cuales se pueden considerar como edades anómalamente jóvenes (Dalrymple \& 


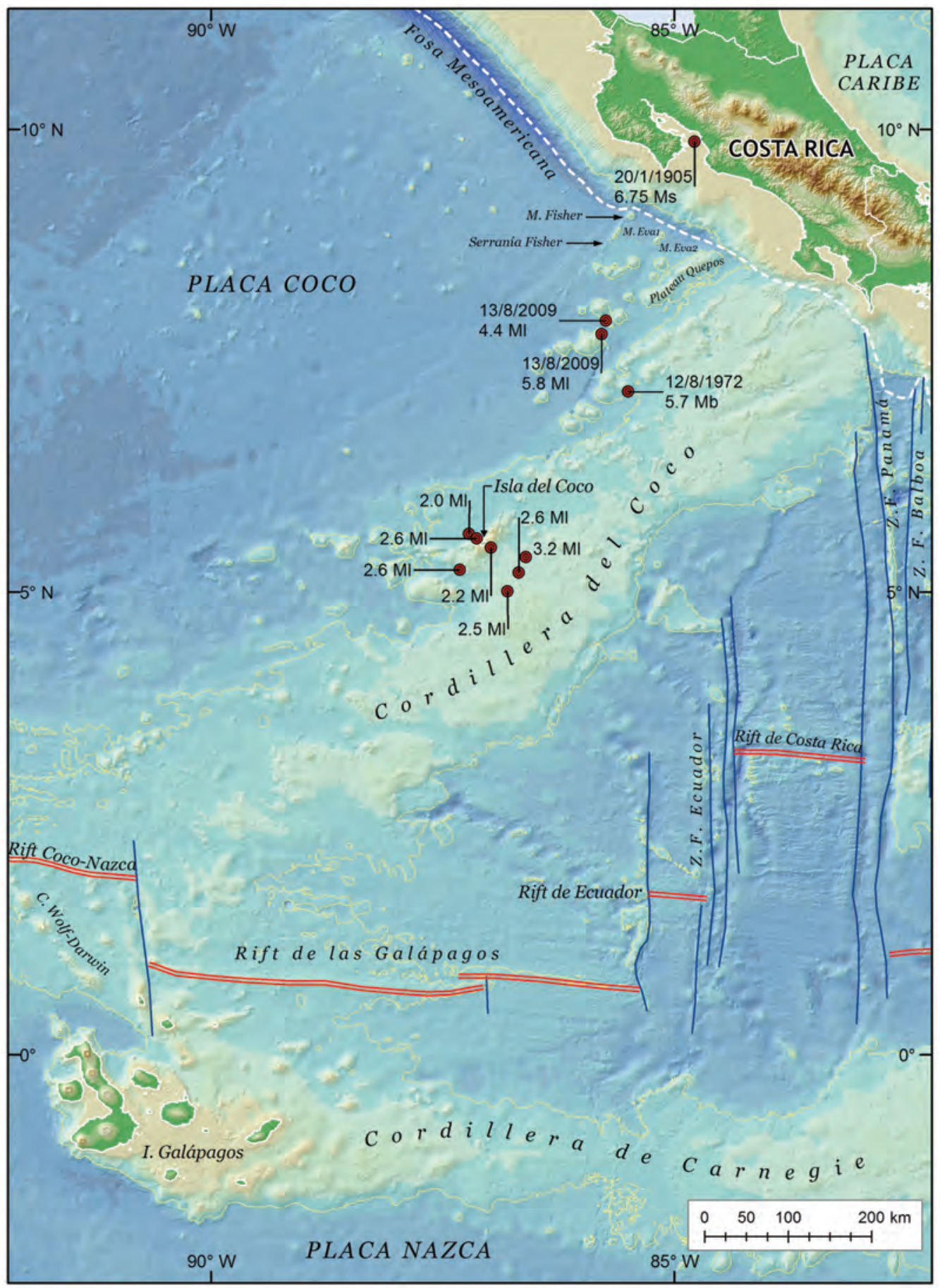

Fig. 1. Mapa morfo-tectónico general, en donde se observa la Fosa Mesoamericana que coincide con el inicio de la zona de subducción de la Placa del Coco bajo la del Caribe, la Zona de Fractura de Panamá, y hacia el SW, casi al centro, un pequeño punto en la Cordillera Volcánica del Coco, que corresponde con la Isla del Coco. Se incluyen los sismos registrados por la estación Sismológica de la Isla del Coco y otros citados en el texto. Se incluyen también los principales rifts (dorsales medio-oceánicas o zona de dispersión o separación de placas). 


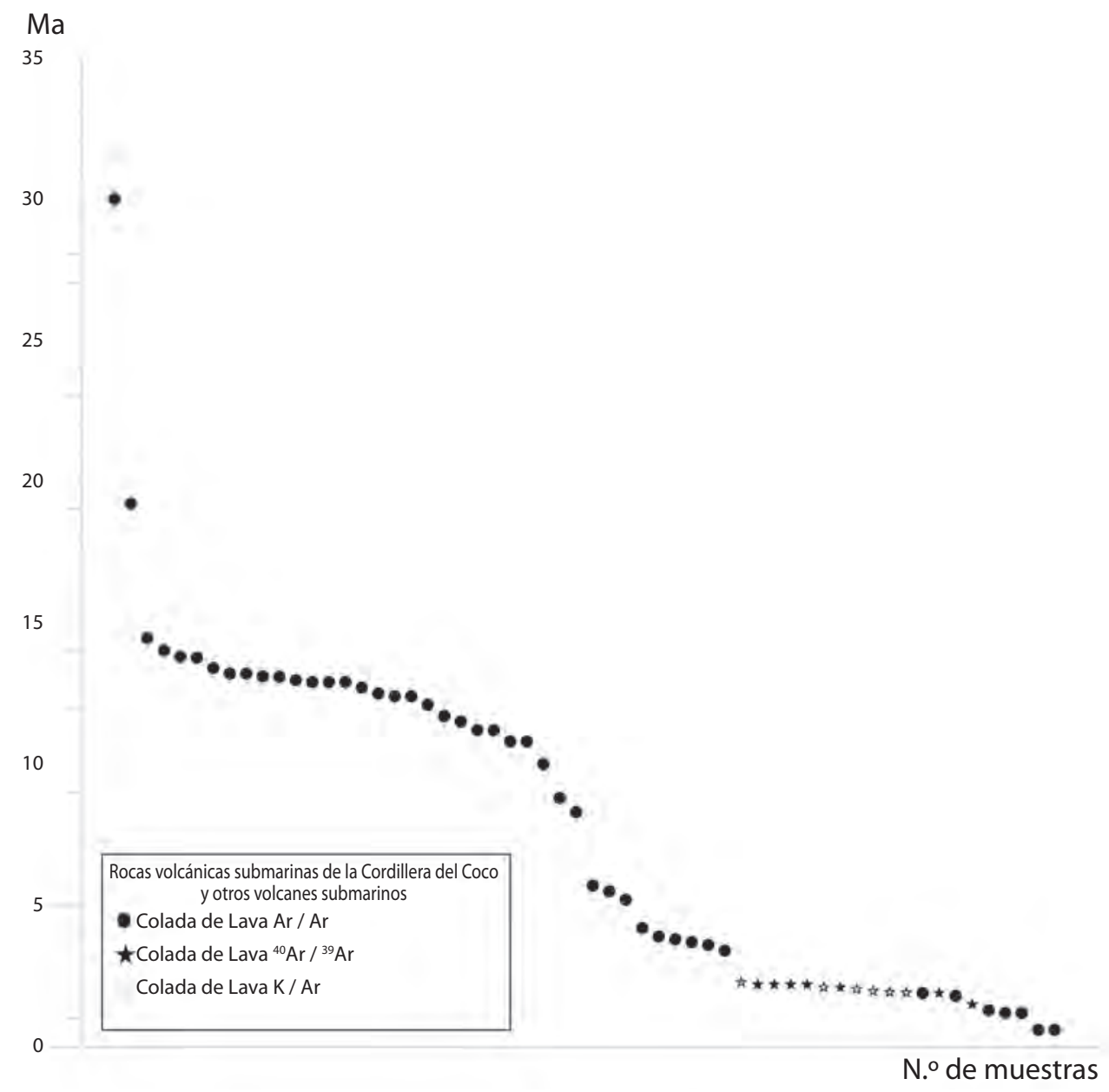

Fig. 2. Dataciones radiométricas en orden decreciente en edad: la Serranía Fisher ( 30 y 19,2 Ma), la Cordillera Volcánica del Coco, incluyendo los volcanes Eva ( 14.5 y 13Ma), la rocas dragadas cerca de plataforma submarina de Quepos y de la costa costarricense ( 14,0-13,0Ma), incluyendo las rocas más recientes, de Isla del Coco (2.2-1.5Ma) e incluso algunos montes submarinos de edad más reciente (ver Alvarado \& Gans, 2012).

Cox 1968, Bellon et al. 1983, Harpp et al. 2005, O’Connor et al. 2007). Lo anterior sugiere que la Isla del Coco es también producto de un vulcanismo local (Pleistoceno Inferior). Es por ello que, actualmente, no resulta fácil relacionar directa y cronológicamente el vulcanismo que dio origen a la Cordillera Volcánica del Coco con el punto caliente de las Galápagos. Por todo esto, también se propuso definir su formación mediante una "línea caliente" (Alvarado 1984).
En efecto, el origen de este vulcanismo relativamente joven, dentro de los paradigmas de la tectónica de placas, es un tema aún abierto a discusión y fuera de los objetivos del presente artículo, a lo que una serie de teorías se han propuesto. La más antigua habla de que puede ser es el producto un "punto caliente" local, es decir una zona relativamente puntual que permite la salida de magma desde el interior de la astenósfera (Burke \& Wilson 1976). Para otros, puede ser una reactivación con bajo grado de 
actividad de la "pluma mantélica" originada en el punto caliente de las Galápagos (Castillo et al. 1988), mediante el rejuvenecimiento del vulcanismo pos-escudo y pos-erosional con cierto control tectónico (Werner et al. 2003, Harpp et al. 2005); es decir, que sea una anomalía amplia del manto de gran longevidad (O'Connor et al. 2007, Gazel et al. 2011) a modo de una línea caliente (Alvarado, 1984). Para otros, puede corresponder con vulcanismo de dorsal oceánica o un punto caliente secundario (Meschede et al. 2000), concordando con el trabajo de Burke \& Wilson (1976). Todos concuerdan, en mayor o menor grado y de modo simplificado, en que se trata de una anomalía térmica del manto que se manifestó mediante el vulcanismo, a través de una zona de debilidad cortical.

Entonces, queda en claro que existen volcanes submarinos en las aguas territoriales de Costa Rica, pese a que todos, o en su mayoría, están extintos. Sus formas varían desde conos típicos hasta mesetas y crestas alargadas, con alturas desde unas pocas decenas de metros hasta $2 \mathrm{~km}$ o más a partir del fondo marino. El número de estos volcanes submarinos, extintos o no, aún no se conoce, y podría superar la centena, entre nuestras costas y más allá de la Isla del Coco (Alvarado 2000). Pese a ello y con base en todo lo anterior, no se excluye, sin embargo, la posibilidad de que al existir esta anomalía térmica en el manto, se pueda dar la formación de nuevos volcanes submarinos a lo largo de la Cordillera del Coco.

\section{SISMICIDAD REGIONAL}

A partir del 2000 se han realizado varios estudios preliminar acerca de las sismicidad de la Isla del Coco y sus alrededores, todo ello dentro del marco de un proyecto de investigación y vigilancia sísmica permanente, por parte de la Sección de Sismología de la Universidad de Costa Rica, por lo que gran parte de este apartado está basado en esas investigaciones (Rojas 2001, 2003, 2009).
Temblor del 12 de agosto de 1972: Rojas (2003) suministra una detallada descripción histórica y bibliográfica sobre este sismo, llamado el temblor de la Isla del Coco. En dicho informe se comenta, que el biólogo costarricense Róger Sáenz, manifiesta que el 12 de agosto de 1972, en la mañana, sin lluvia y nublado, se encontraba frente a la playa de Bahía Wafer cuando sintió un sismo intenso. Luego de unos segundos de haberse iniciado, observó deformaciones en la arena de la playa, la cual "saltaba", acompañada de chorritos de agua (i.e. licuación o licuefacción) mientras el sismo continuaba. No observó variaciones en el nivel del mar ni en el oleaje. Escuchó fuertes "ruidos sísmicos" y observó que ocurrían deslizamientos de rocas y caían algunos árboles de las laderas. Mientras temblaba, los mamíferos corrían y hacían ruidos (i.e. cerdos de monte y ratas), gran cantidad de aves salieron en bandada, volando ascendentemente en grupo y se quedaron volando en círculo; pasado el sismo, regresaron a los árboles. Estima que el sismo tuvo una duración de unos 45 a 60 segundos, con algunas sacudidas fuertes que le dificultaron el caminar. Luego fue a la casa donde se hospedó (con estructura de madera y piso de cemento), observó que, había rajaduras en el piso y varios objetos caídos, pero sin daños mayores. Por la descripción de los efectos y los daños, Rojas (2003) estima que la intensidad máxima del sismo del 12/08/72 a 07:15, fue de VII (escala de Mercalli Modificada, MM), en la Isla del Coco. Hasta el momento no hay informes de que fuera sentido en alguna otra parte de Costa Rica, Panamá, Ecuador o Colombia, ni de que haya generado algún tsunami.

Cerca del medio día, cuando estaban almorzando en la playa, sucedió otro sismo de menor intensidad. En el transcurso de las siguientes dos semanas percibió algunos otros sismos pero más leves. Durante las horas posteriores al sismo, y al día siguiente, caminó por el cauce del Río Genio, observando varios deslizamientos de rocas y árboles caídos. Manifiesta que se percibía un olor como sulfuroso "o 
de gases orgánicos" dentro del cañón del río. Este olor a gases sulfurados, indicado por el Sr. Sáenz, en los alrededores del cauce del Río Genio, posiblemente fue debido a que la licuefacción, los deslizamientos y las fracturas causaron la salida de gases (e.g. metano, sulfuro de hidrógeno) producidos por la descomposición de la materia orgánica confinada en el suelo.

En el estudio de Adamek et al. (1988), reportan el sismo como localizado a unos 300 $\mathrm{km}$ al este de la Isla del Coco, con un mecanismo focal transcurrente dextral (movimiento relativo del bloque deslizante, opuesto a la falla, hacia la derecha), con rumbo N-S y lo asocian al sistema de fracturas de Panamá. La Red Sismológica Mundial lo ubica a unos $150 \mathrm{~km}$ al SE. Sin embargo, dada la escasa cobertura instrumental sismográfica en esa época para la región, la ubicación asignada puede presentar incertidumbres y errores. Además, debido a la magnitud moderada del sismo y a la forma como fue percibido, este podría estar ubicado a menor distancia de la Isla del Coco (menos de 100km, hacia el SE). Por esta nueva ubicación sugerida y por el tipo de mecanismo focal, este evento puede estar asociado a alguna de las fallas del borde este de la Cordillera Volcánica de Coco, correspondiente con los sistemas paralelos de la Zona de Fractura de Panamá, tal como han sido propuestos por Castillo et al. (1988).

Evento: 12 de agosto de 1972.

Hora local: 07h:15,

Magnitud: $5.7 \mathrm{M}_{\mathrm{b}}\left(\mathrm{M}_{\mathrm{b}}\right.$ es equivalente a la magnitud en la escala Richter y se basa en la interpretación de las señales de las ondas internas $\mathrm{P}$ y S).

Profundidad: Posiblemente superficial, $\leq 10 \mathrm{~km}$. Ubicación posible: $150 \mathrm{~km}$ al NE de la Isla del Coco. Latitud: $\sim 07^{\circ} 10.00^{\prime}$ Long: $-85.30 .00^{\prime}$ (Fig. 1).

Intensidad máxima (MM): VI-VII en Isla del Coco.

Más recientemente, Rojas (2001) comenta que el terremoto de El Salvador del 13/01/2001,
7.6 $\mathrm{M}_{\mathrm{w}}$ generó una intensidad en la Isla del Coco, de III (MM).

Los temblores del 13 de agosto del 2009: Al observar el mapa mundial de sismicidad del Servicio Geológico de los Estados Unidos (USGS), la actividad sísmica de importancia en esta región entre 1990 y 2006 es casi nula, o a lo sumo algún sismo cercano de magnitud menor. Más recientemente, durante la madrugada del 13 de agosto, 2009, se registraron dos sismos de magnitud moderada, ubicados a media distancia entre Cabo Blanco y la Isla del Coco, en un área en donde no es usual la generación de sismos. Los eventos fueron bien registrados por la estación sismológica de banda ancha de la RSN en la Isla del Coco, y cuyas señales sísmicas se muestran en la Fig. 3. Las características de estos sismos son las siguientes (Rojas 2009):

Evento: 13 de agosto de 2009

Hora local: $03 \mathrm{~h}: 38$ '

Magnitud: $5.8 \mathrm{M}_{1}\left(\mathrm{M}_{1}\right.$ o magnitud local, equivale a la magnitud local en la escala Richter, y se establece con base en la amplitud máxima de la onda S).

Profundidad: $14 \mathrm{~km}$

Ubicación: $250 \mathrm{~km}$ al SW de Cabo Blanco. Latitud: $07^{\circ} 47.34^{\prime}$ Long: $-85^{\circ} 47.20^{\prime}$. RMS: 0.39 .

Intensidad (MM): III en Valle Central, Jacó y Zarcero.

Evento: 13 de agosto del 2009

Hora local: 04h:22'

Magnitud: $4.4 \mathrm{M}_{1}$

Profundidad: $10.0 \mathrm{~km}$

Ubicación: $250 \mathrm{~km}$ al SW de Cabo Blanco. Latitud: $07^{\circ} 56.04^{\prime}$ Long: $-85^{\circ} 44.40^{\prime}$. RMS: 0.65 .

Intensidad (MM): No fue reportado como sentido en el territorio continental ni en la Isla.

Estos eventos relativamente importantes, generados bajo la Cordillera Volcánica del Coco, son poco usuales en nuestro territorio marítimo. Según el análisis del mecanismo focal, el tipo de ruptura tectónica (Figs. 1 y 3 ) 


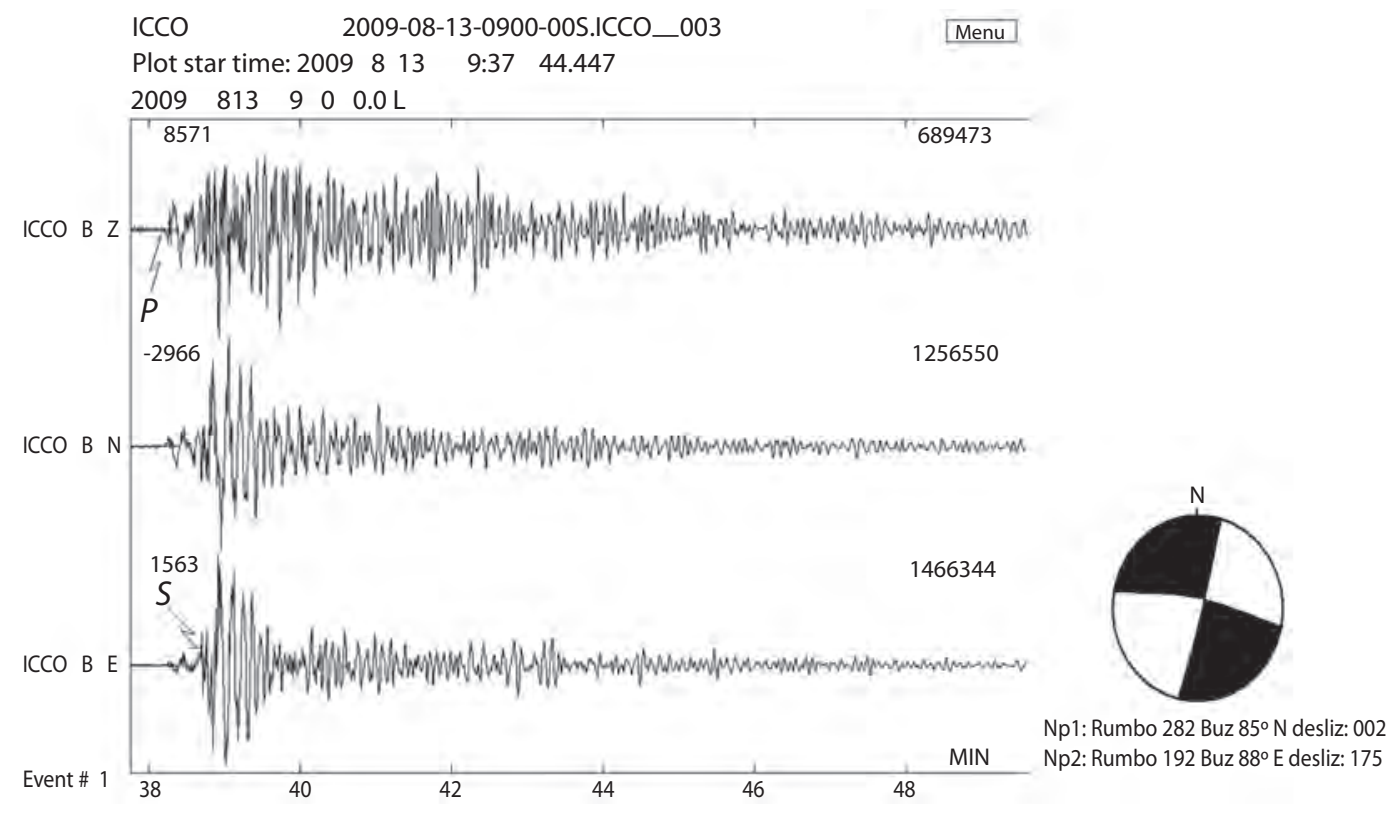

Fig. 3. Sismogramas registrados por la estación de la Isla del Coco, del evento del 13/08/09 a 03:37 Hora Local, con magnitud determinada con base en el momento sísmico $\mathrm{M}_{\mathrm{w}}=5.8$. Se presenta el mecanismo focal del sismo reportado por el USGS, interpretado como una falla N-S con movimiento dextral, con base en el plano nodal escogido basado en el contexto tectónico (Rojas 2009).

de éstos sismos se puede relacionar con una falla con dirección N-S (plano nodal escogido con base en la tendencia tectónica local), y que pueden corresponder con una prolongación de una de las fallas dentro de la placa oceánica, que se extienden desde el rift o dorsal del Ecuador y Costa Rica hacia el norte hasta la Cordillera Volcánica del Coco, y que, al mismo tiempo, son paralelas a la Zona de Fractura de Panamá (Fig. 1). La actividad en este sistema de fallas parece indicar una posible migración de la actividad hacia el oeste desde la Zona de Fractura de Panamá, como ya lo habían mencionado algunos investigadores, entre ellos Meschede et al. (2000).

\section{GEOLOGÍA LOCAL}

Aspectos estratigráficos y petrográficos: La Isla del Coco es de origen volcánico y está constituida por la acumulación de una serie de coladas de lava, diques y rocas piroclásticas (rocas producto del vulcanismo explosivo, como tobas, algunas con lapilli acrecional, brechas explosivas), y con pequeñas playas de arenas y cantos rodados (Chubb 1933, Malavassi 1982, Alvarado 1984, Castillo et al. 1988; Lockwood \& Benumof 2000). Existen también algunos arrecifes coralinos y otros cuerpos biogenéticos importantes.

Punta Presidio, el promontorio que separa la Bahía Wafer de la Bahía Weston, está constituida por una sucesión de coladas de lava tipo aa, término que se refiere a coladas formadas por una porción escoriácea y brechosa superior y por una porción más densa inferior. La sección inferior está compuesta por coladas entre 1 y menos de $10 \mathrm{~m}$ de espesor, excepcionalmente $30 \mathrm{~m}$; la sección superior, por coladas de lava con un espesor mucho más potente, usualmente superior a los $10 \mathrm{~m}$. Este cambio en el grosor se podría interpretar como el resultado de un incremento en la viscosidad del magma originario en la sección superior. Estas coladas 
de lava, con espesores superiores a los $100 \mathrm{~m}$ en algunos casos, y con un buen desarrollo de estructuras columnares, son el resultado del proceso de enfriamiento de varias unidades de flujo espesas, luego de la emisión casi simultánea de las coladas, tal y como se observa en la Bahía Wafer, cerca de Punta Gissler (Malavassi 1982, Castillo et al. 1988). En Punta Presidio existe una estructura ovoide; contiene fracturas radiales y concéntricas sobre-impuestas que sugieren un túnel de lava relleno y enfriado lentamente (Malavassi 1982). Las coladas de lava y los depósitos de rocas piroclásticas tienen una composición de traquitas (traquiandesitas basálticas, traquiandesitas), y de basaltos alcalinos con olivino (hawaitas, mugearitas), algunos pocos con olivino y hornblenda (Malavassi 1982, Alvarado 1984, Castillo et al. 1988, Harpp et al. 2005).

La estratigrafía y cronología generalizada de la Isla del Coco (Castillo et al. 1988, Lockwood \& Benumof 2000) sería entonces la siguiente (Fig. 4):

1. Serie Volcánica Inferior, de $80 \mathrm{~m}$ de espesor visible en el extremo sur de la Isla del Coco. Por lo general se observan menos de $20 \mathrm{~m}$ continuos en los afloramientos

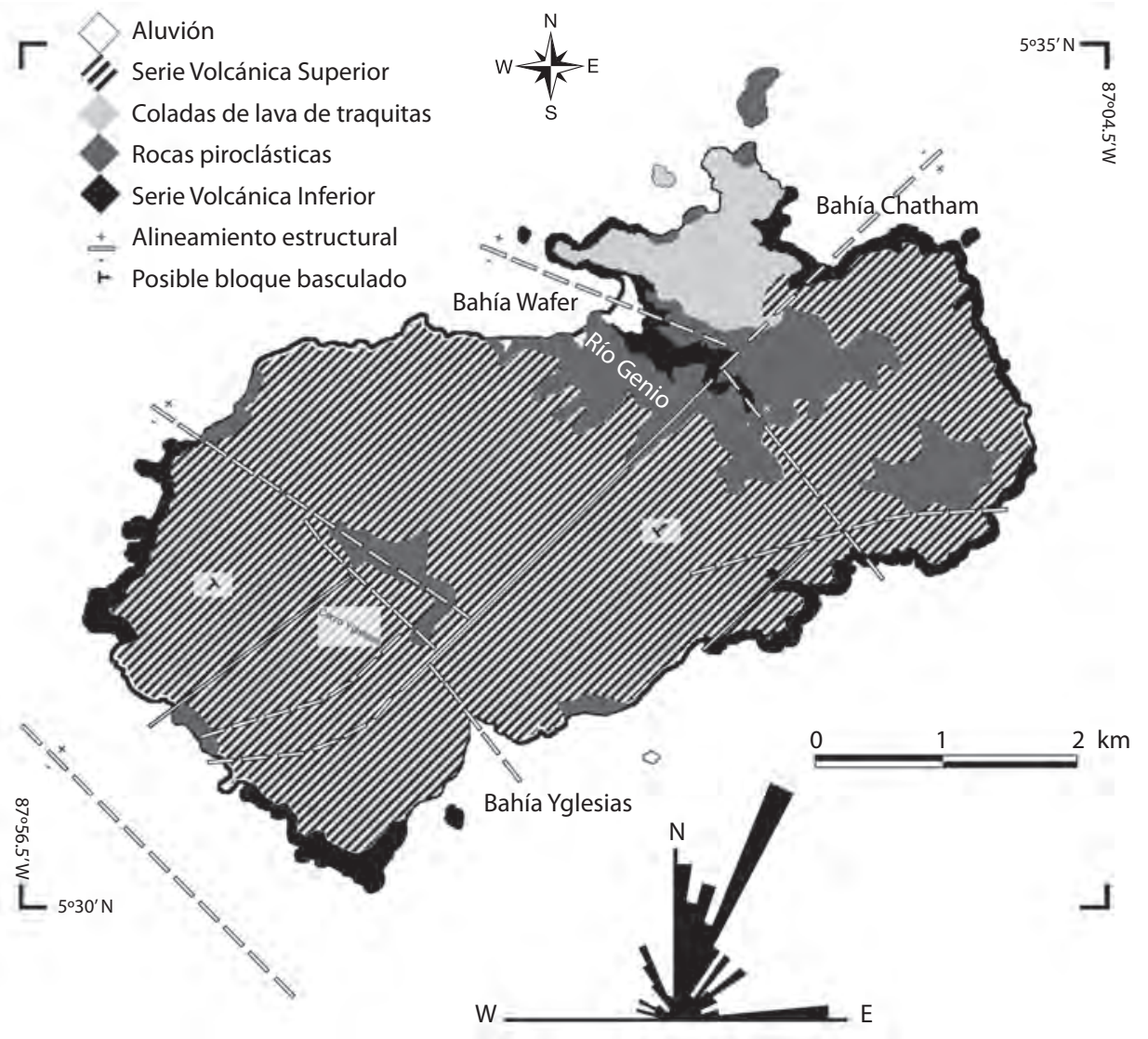

Fig. 4. Unidades geológicas de la Isla del Coco (basado en Castillo et al. 1988). Se incluyen la rosa de frecuencias de estructuras (diques, diaclasas principales, fallas). La mayoría de los diques se ubican en las secuencias antiguas e intermedias, mientras que las fallas cortan todas las secuencias (Castillo et al. 1988). Se recalcaron y redibujaron los alineamientos en correspondencia con la posición de fallas probables, con base en Lockwood y Benumof (2000) y en los alineamientos geomorfológicos y la morfología de la red de drenaje de los ríos. Estos elementos sugieren basculamientos (inclinación de las geoformas según lo marcan las buzamientos con flecha). Falta comprobar en el campo la mayoría de las estructuras grandes demarcadas. 
individuales. Se compone de coladas de lava basálticas de tipo aa (término hawaiano utilizado en vulcanología para indicar coladas espinosas, difíciles de transitar) de $2 \mathrm{~m}$ de espesor o menos, pero hacia el tope de la sección estratigráfica, suelen cambiar a coladas pahoehoe (termino hawaiano utilizado para indicar coladas fluidas y de superficie lisa u ondulada, fácil de transitar) o, en ciertos casos, a coladas espesas en bloques y separadas por paleosuelos (indicadores de una formación subaérea), autobrechas y sedimentos volcaniclásticos, expuesta en la base de los acantilados, alrededor de la Isla del Coco y en el Río Genio.

2. Unidad Piroclástica, que sobreyace discordantemente a la anterior, de unos $80-100 \mathrm{~m}$ de espesor, observada en la Bahía Wafer hasta el oeste del Río Genio y por el Río Yglesias (también escrito como Iglesias), constituida por tobas y lapillitas (rocas constituidas de cenizas y fragmentos de piroclastos gruesos litificados, respectivamente), algunos retrabajados en ambiente fluvial o marino, otros bien estratificados y con estructuras de dunas, sugiriendo un origen explosivo rasante de tipo oleada piroclástica. Otros depósitos son de origen marino probable, representada por brechas volcánicas y areniscas, mezclada con tobitas ácidas, incluyendo los depósitos freato-magmáticos (depósitos explosivos producto de la interacción magma-agua) presentes en la Isla Manuelita. Algunas coladas delgadas de traquita pueden estar presentes. Dentro de esta unidad aparecen diques de traquita delgados (menos de $1 \mathrm{~m}$ de espesor) y cuerpos dómicos pequeños (unos 20m de diámetro). Figs. 5 y 6.

3. Cuerpo dómico (cúpula de lava) de traquita, expuesto en la parte norte de la Isla del Coco, separa las bahías de Wafer y Chatham y también aparece una pequeña isleta al norte.

4. Serie Volcánica Superior de unos $300 \mathrm{~m}$ de espesor en el oeste y apenas unos $10 \mathrm{~m}$ el tope del domo. Las lavas son masivas $(5 \mathrm{~m}$ o más de espesor) con marcada disyunción columnar y lentes de escorias y de cenizas, posiblemente procedentes de la actividad de algunos conos secundarios (Fig. 7).

5. Diques basálticos delgados (menos de $1 \mathrm{~m}$ de espesor), los cuales suelen cortar todas las unidades precedentes y evidentemente son más abundantes en las unidades más antiguas.

6. Depósitos recientes (últimos 10000 años o menos) de deslizamientos, coluvios, aluviones, suelos y depósitos de playa.

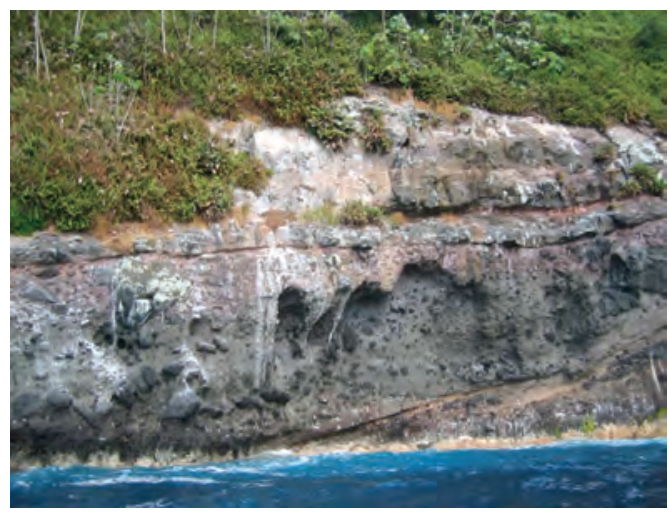

Fig. 5. Alternancia de brechas basálticas (¿flujos de escombros volcánicos?) con coladas de lava delgadas y paleosuelos quemados (color rojizo), en el sector suroeste de la Isla del Coco (Fotografía por Jorge Cortés).

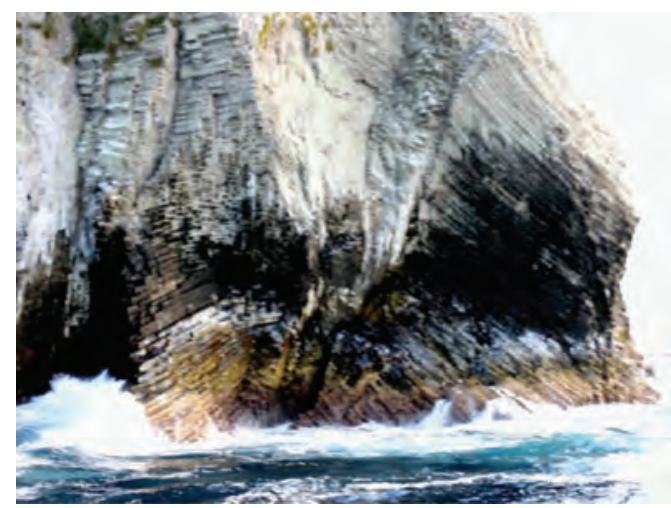

Fig. 6. Cuerpo de lava con disyunción columnar (y posible fallamiento) en donde se han desarrollado prismas a causa del proceso de enfriamiento diferencial de la lava. Isla Juan Bautista (también conocida como Isla Cónica o Vancouver) del lado SE de la Isla del Coco (Fotografía por Jorge Cortés). 


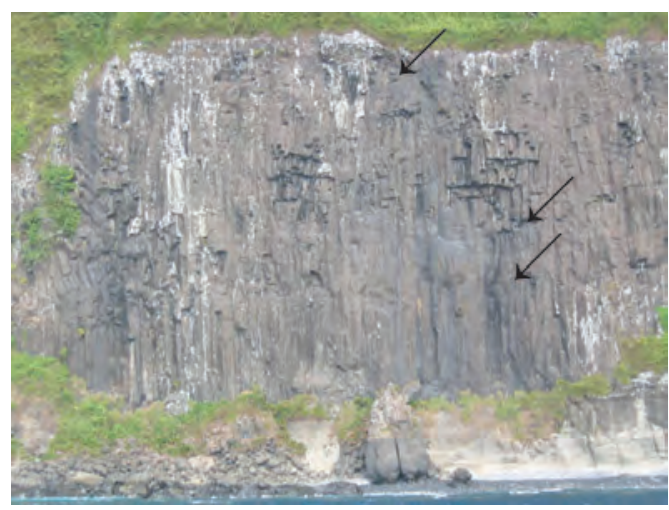

Fig. 7. Coladas de lava de la Serie Volcánica Superior, las cuales forman varias coladas de lava compuestas (posibles contactos señalados por las flechas), casi como una única unidad de enfriamiento, en los acantilados localizados en Bahía Yglesias. A la izquierda se observan bloques de lava caídos (coluvios) y siendo removidos por las olas (Fotografía por Jorge Cortés).

Castillo et al. (1988) proponen la siguiente historia geológica de la Isla del Coco, que en este trabajo se reinterpreta con base en la información de las dataciones radiométricas previamente citadas, que se ofrece a continuación:

a. Vulcanismo tipo escudo (volcán con laderas de suave pendiente), el cual edificó las rocas más antiguas o la Serie Inferior (2.2-1.97Ma).

b. Erupciones piroclásticas con la posible formación de una caldera (gran depresión volcánica) e intrusiones localizadas de traquita (aproximadamente 1.96-1.92Ma?).

c. Erupciones fisurales (vulcanismo a lo largo de una falla), que se verificaron cuando menguaba el vulcanismo explosivo (1.91-1.51Ma).

Un aspecto fundamental de todo lo anteriormente expuesto, es lo referente a la colonización biológica de la Isla del Coco y su evolución hasta generar especies endémicas. Ya Dalrymple y Cox (1968) habían llamado la atención al concluir que las evidencias geológicas obtenidas por ellos estaban en acuerdo con la idea de que la Isla del Coco pudo ser un punto rocoso de apoyo en la migración de organismos desde y hacia las Galápagos. Aunque lo anterior no es del todo válido, dado que se conoce que el Archipiélago de las Galápagos es más antiguo pero aún volcánicamente activo (19-0Ma), si es muy probable que existiera intercambio entre las diferentes islas ya sea por las corrientes marinas o las aves.

Rasgos hidrogeológicos: No existen datos hidrogeológicos en la Isla del Coco, aunque es claro que deben de existir acuíferos locales y acuitardos, entre otros, bajo ese medio volcánico estratificado, con capas muy permeables por sus fracturas y poros (coladas de lava, autobrechas, tobas, arenas de playa) y otras poco permeables (paleosuelos quemados por el vulcanismo, depósitos piroclásticos).

Aspectos geomorfológicos: La Isla del Coco, de unos $24 \mathrm{~km}^{2}$ (aprox. 7 x $5 \mathrm{~km}$ ) de selva, presenta barrancos profundos, acantilados, valles, riachuelos torrenciales y cascadas.

La Isla del Coco es la única isla oceánica por definición, es decir que está fuera de la plataforma continental de Costa Rica (Cortés 2007). Su altura máxima es el Cerro Yglesias $(575 \mathrm{~m})$. Aunque se ha argumentado una estructura cratérica en el Cerro Yglesias (p.ej. Bergoeing 1994, mapa inédito incluido en Bergoeing 1998), dada la antigüedad relativa de la isla bajo un clima tropical lluvioso, estos rasgos parecen corresponder más bien con estructuras de inestabilidad de laderas y deslizamientos en forma de herradura. Por ejemplo, Wafer (1685 en Chubb 1933) anota:

[...] Muchos manantiales en la cima de los cerros envían sus aguas frescas y potables a un profundo depósito o lago, de fondo cóncavo..."

Chubb (1933) comenta al respecto:

[...] Esta expresión sugiere la existencia de un lago cratérico, pero resulta difícil comprender cómo, bajo un régimen de lluvias tropicales, puede haber conservado su forma original y resistido a la erosión durante el largo período, a juzgar por la altura de los acantilados, transcurrido desde la formación de la isla..." 
Los sectores de playa arenosa mejor desarrollados de la Isla del Coco se ubican en Bahía Wafer. Otras playas con un desarrollo incipiente, con acumulación de cantos de playa principalmente (playas de bloques y cantos), están ubicadas en las bahías Chatham e Yglesias (Figs. 4 y 7).

El rasgo básico de la morfología litoral está constituido por acantilados elevados de hasta $183 \mathrm{~m}$ de altura, casi verticales, formados por rocas volcánicas $\mathrm{y}$, desde donde los riachuelos forman saltos y cascadas. La disyunción columnar (prismas de rocas, Figs. 6 y 7) de las potentes coladas de lava ha favorecido la formación de estos acantilados vivos, así llamados por estar activos, debido a que se encuentran en proceso de erosión regresiva intensa y socavación causadas por el oleaje constante en su base. Algunos acantilados tienen en su base depósitos originados por la acumulación de deslizamientos y caídas de bloques. La ausencia casi total de playas en la Isla del Coco se debe a la actividad intensa de las olas, que no permiten la acumulación del material, y a la existencia de aguas relativamente profundas cerca de los acantilados.

Otro rasgo muy característico de la morfología litoral, es la presencia de cavernas y túneles marinos (Lockwood \& Benumof 2000); incluso, se han visualizado arcos marinos sumergidos (Fig. 8). La plataforma insular de la Isla del Coco posee profundidades variables de entre $110 \mathrm{~m}$ al NW y $183 \mathrm{~m}$ de profundidad para el resto de la Isla. A partir de allí, se inicia el talud marino, con pendientes comparativamente más pronunciadas (Lizano 2001), que denotan capítulos diversos de la historia de la isla. Por un lado, los acantilados vivos, con cascadas y valles colgados y con la existencia de tan solo dos playas bien definidas, son indicativos de que la Isla del Coco se encuentra dentro de un proceso erosivo intenso y actual. Por otro lado, los arcos sumergidos, a profundidades de incluso $90 \mathrm{~m}$, son indicadores o de un proceso de subsidencia de la isla o de un ascenso del nivel del mar después del deshielo de la última glaciación, o de ambos. En todo caso, quedaron preservados de la erosión superficial. En
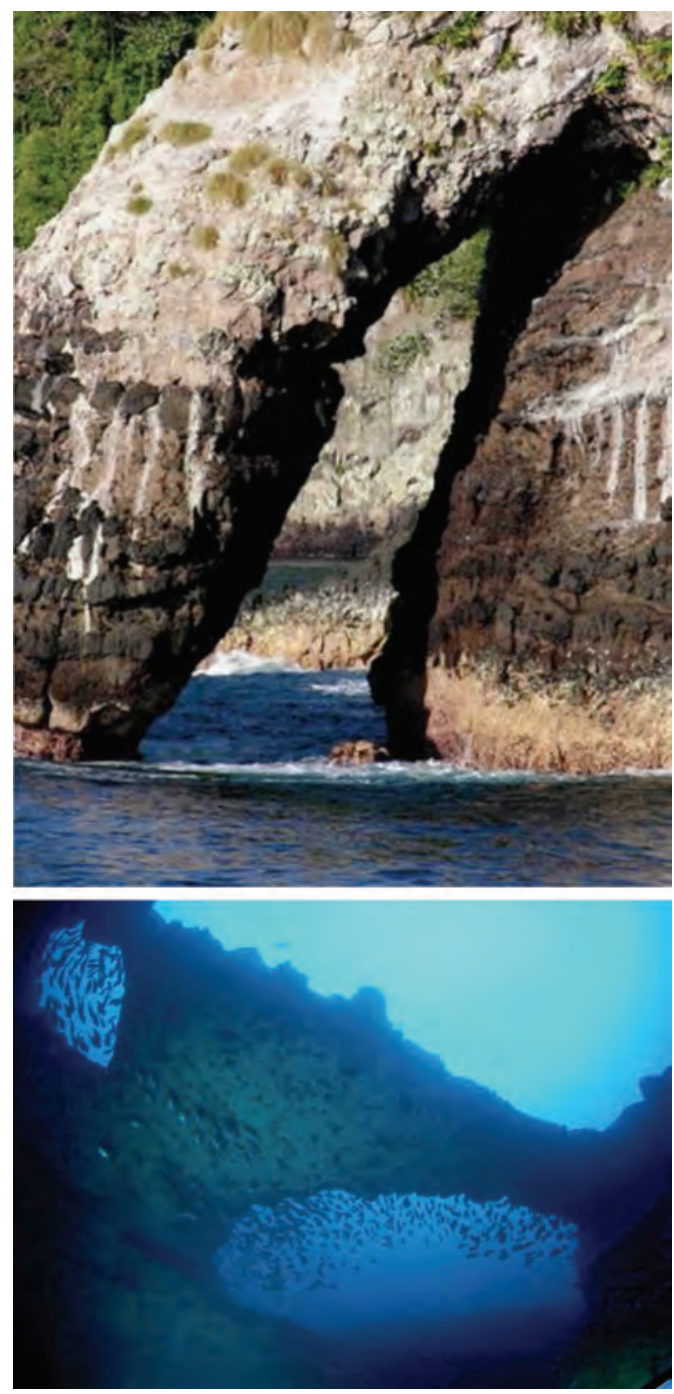

Fig. 8. Arcos naturales producto de la erosión marina en coladas de lavas delgadas y rocas piroclásticas. Mientras que uno de ellos es subaéreo, localizado en Isla Muela, Bahía Yglesias (Fotografía por Jorge Cortés), los otros dos son submarinos y se ubica a $90 \mathrm{~m}$ de profundidad (Fotografía por Undersea Hunter Group).

efecto, el nivel del mar, durante la última máxima glaciación, hace $\sim 18000$ años, descendió unos 110 a $130 \mathrm{~m}$, incluso quizás hasta $160 \mathrm{~m}$ (Fairbanks 1989, Fleming et al. 1998, Muhs et al. 2003), lo cual podría explicar fácilmente la existencia de los arcos sumergidos y del primer nivel de plataforma submarina a $110 \mathrm{~m}$. El otro 
nivel más difuso, a $183 \mathrm{~m}$, podría ser el resultado de otro periodo glaciar anterior, quizás el máximo registrado hace $\sim 130000$ años, con un descenso de 130-155m (Rabineau et al. 2006), pero más investigación es requerida.

No hay que olvidar que con probabilidad existe una subsidencia paulatina del escudo volcánico del Coco, debido a su enfriamiento térmico, al peso del escudo volcánico y al lento movimiento de la placa hacia aguas más profundas, aunado una tectónica relativamente activa, que divide a la Isla del Coco y las montañas submarinas aledañas, en varios bloques principales (Figs. 4 y 9). Pero nuevamente, más estudios de detalles se requieren para cuantificar y soportar las ideas acá expuestas, en particular mediante mediciones GPS de precisión.
Tectónica y sismicidad: Las estructuras geológicas dominantes en la Isla del Coco son fracturas (en algunos cosos rellenos por diques volcánicos) y algunas fallas con rumbos dominantes NE hasta N-S (Castillo et al. 1988). Mientras que algunos autores reportan fallas pequeñas (Castillo et al. 1988), en cambio otros sí cartografiaron algunos alineamientos fotogeológicos como fallas posibles que atraviesan toda la isla (Bergoeing, 1994 en Bergoeing 1998) e incluso algunas fueron indicadas en el campo, como las que se observaron en las bahías Wafer y Chatham, postulada como una falla en tijera, pero que no muestra signos de actividad o movimientos holocenos, aunque argumentan que "es una zona de debilidad que podría sufrir rupturas futuras" (Lockwood \& Benumof 2000). Algunas posibles fallas

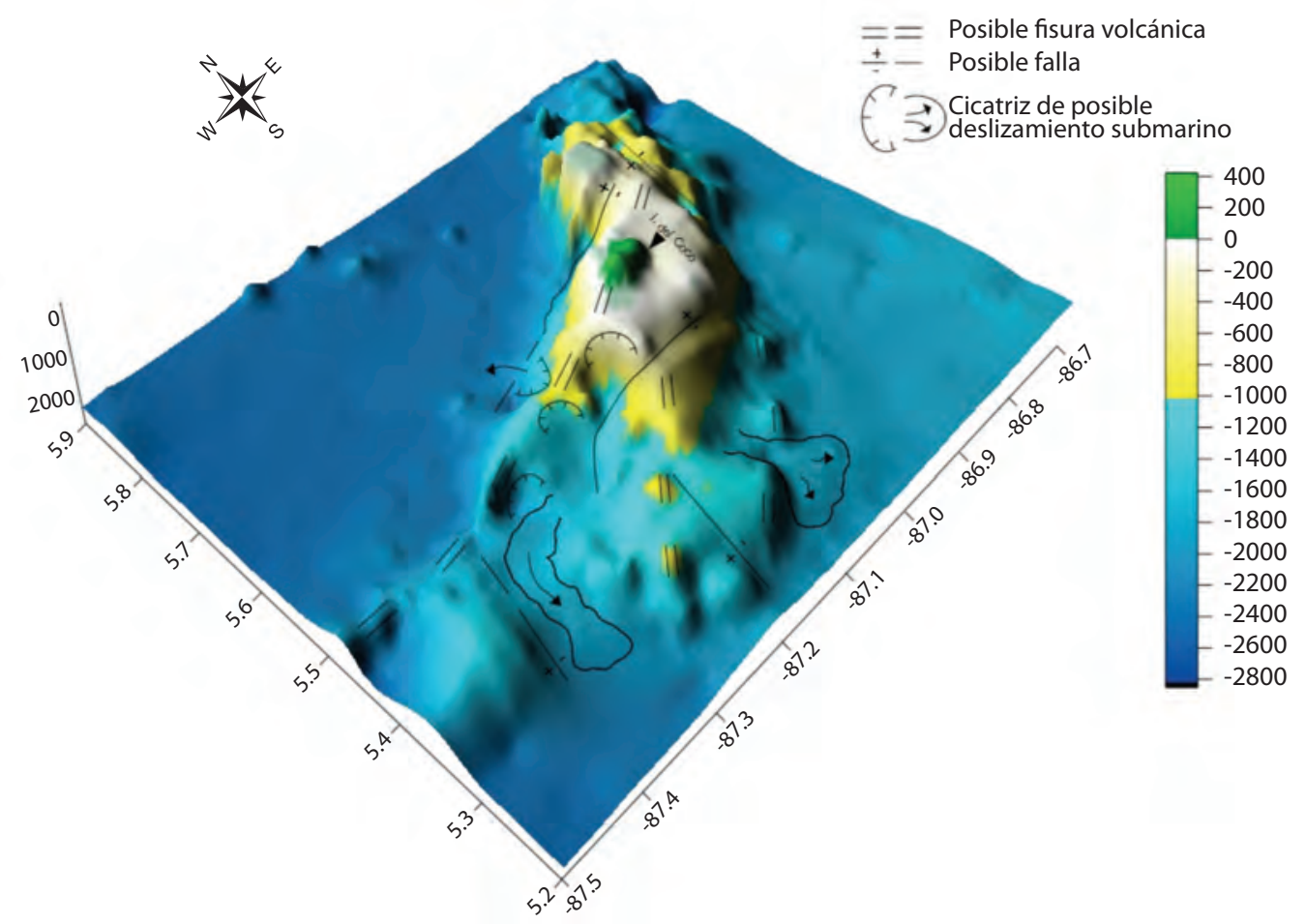

Fig. 9. Modelo tridimensional de la Isla del Coco y sus montanas submarinas vecinas (Lizano, 2012). Se presenta una interpretación geológica preliminar, en donde se observan tres serranías de diferente tamaño, orientadas NE, posiblemente en correspondencia con fisuras eruptivas, varias montañas submarinas (seamounts) en probable correspondencia con volcanes (escudos, estratoconos y conos de escorias), y varios escarpes con rumbo N-S y ENE, en correspondencia probable con fallas corticales y algunas morfologías submarinas con forma acucharada y pendientes suaves a sus pies, posiblemente relacionadas con cicatrices y depósitos de deslizamientos. 
importantes se pueden hipotetizar con base en los rasgos geomorfológicos (ver Fig. 4). Poseen rumbos principales NE y NW con longitudes mínimas entre 1 y $7 \mathrm{~km}$, inferidas por los alineamientos topográficos y cambios de facies. Efectivamente, dos de estos alineamientos merecen atención, dado que son morfológicamente importantes y poseen un rumbo NW-SE: uno cortando al Cerro Yglesias, y el otro entre la Bahía Wafer, Punta Presidio y Roca Montagne. Ambos dejan entrever las secuencias estratigráficas más antiguas. De existir dichas estructuras, sería posible dividir la Isla del Coco en varios bloques morfotectónicos, con el bloque central basculado, al parecer, hacia el $\mathrm{NE}$, tal y como lo atestiguan la red de drenaje fluvial. Puesto que la Isla del Coco posee una edad de entre 1 y $2 \mathrm{Ma}$, dichas fallas tendría una edad máxima del Pleistoceno Inferior, es decir del Cuaternario. Se desconoce su edad mínima y mucho menos su grado de actividad (en el caso de tenerla), por lo que no se puede excluir que sean potencialmente activas.

Los modelos batimétricos tridimensionales de la Isla del Coco y sus alrededores (Lizano 2012), dejan entrever que la Isla es tan solo la expresión subaérea de un escudo volcánico de evolución compleja, originado por al menos tres alineamientos de montañas submarinas o sierras, con rumbo NE y volviéndose más profundas al SW de la isla (Figs. 1 y 9). Estas sierras, al parecer, son el producto de un vulcanismo fisural con dichos rumbos. Algunas fallas posibles con rumbo N-S y ENE, parecen afectar la estructura submarina, además de la presencia de abanicos submarinos probables, producto de la acumulación de deslizamientos, algunos de los cuales podrían ser contemporáneos con la actividad sísmica (¿co-sísmicos?) y/o volcánica.

En marzo del 2000 se instaló la primera estación sismográfica (de una componente vertical), la cual registró del 03 al 30 de marzo del 2000, 18 sismos con magnitudes $M_{c}$ que variaron entre 0.01 a 2.9 y con distancias inferiores a $100 \mathrm{~km}$. Entre ellos, hay 11 eventos con una distancia inferior a $20 \mathrm{~km}$ de la Isla del Coco, tres entre 25 y $100 \mathrm{~km}$ y cuatro más distantes aún. En julio del 2000 se instaló la estación permanente (ICO) de tres componentes. El 24 de setiembre del 2001, la estación fue activada nuevamente. Dentro de los cortos períodos que ha funcionado la estación sismológica ICO, se han logrado ubicar, de forma confiable, la actividad sísmica en la Isla del Coco y sus alrededores, lo cual evidencia la presencia cercana de fuentes sísmicas activas. Los epicentros se distribuyen cubriendo un abanico de alrededor de $180^{\circ}$ entre el noroeste y el sureste de la Isla del Coco (Rojas 2001).

\section{AMENAZAS DE LA GEODINÁMICA INTERNA Y EXTERNA}

Para la evaluación de las amenazas geológicas, hay dos fuentes de información, a) aquella que el registro geológico haya dejado preservada (depósitos o sedimentos, cicatrices) y b) la histórica (escrita o verbal) que se conserva. En que una isla de extensión pequeña, alejada de poblados importantes y que ha estado habitada discontinuamente desde su descubrimiento, es de esperar que los registros sean pobres y fragmentarios, pero que igualmente han sido evaluados.

Vulcanismo: Tanto los volcanes submarinos (seamounts) que rodean a la Isla del Coco como las propias estructuras volcánicas de la Isla (p.ej. Cerro Yglesias y Domo Presidio), son las partes culminantes de un gran volcán submarino, poseen edades entre 2.2 y $0.6 \mathrm{Ma}$. Aunque se asume que dichos volcanes están extintos por su edad, aunado al hecho de que no han presentado actividad histórica o inclusive en los últimos 10000 años, su juventud relativa, desde el punto de vista geológico, es decir del Pleistoceno, y por el hecho de que todavía requieren de estudios más detallados, no permite excluir la probabilidad de la formación de un volcán en algún sector aledaño a la Isla del Coco. No obstante, resulta claro que la posibilidad es remota pero no nula.

Tsunamis: La Isla del Coco ha sido afectada por maremotos o tsunamis, tal y como aquel 
originado en la zona sísmica de Nicoya el 20 de enero de 1905 (magnitud calculada con base en las ondas superficiales $M_{S} 6.75$ ), según se interpreta del relato que suministra Gissler a Agustín Guido (en Weston 1992) referente a la expedición realizada en febrero de 1905 (Arias 1990, Alvarado 2000):

"Recayó la conversación sobre el temblor del 20 de enero, que fue en Puntarenas un terremoto. Nos dijo que jamás se habían sentido temblores en la isla [del Coco]; pero que en esa fecha como a las 8 de la noche, comenzando la marea a vaciar notó con sorpresa que en menos de cinco minutos se retiró el mar más de 69 pies; y no habían transcurrido 8 minutos, cuando volvió con tal impetuosidad y ruido, que inundó todo el patio, arrancando algunas palmeras próximas a la boca del río; que el fenómeno le hace prejuzgar la existencia de un volcán submarino cercano a la isla, con cuya opinión estamos de acuerdo, pues desde hace cuatro años que se experimentó en Puntarenas y en la península de Nicoya un temblor casi igual al del 20 , concebimos la sospecha de la existencia de un volcán submarino en nuestra vecindad".

Con respecto al gran terremoto de Valdivia, Chile, 1960, el más grande de que se tenga registro histórico, no se conocen registros de efectos en la isla, dado que posiblemente en ese momento no había población o visitantes.

Otro tsunami observado por personeros del Parque Nacional de la Isla del Coco, fue el que originó se en las islas Samoa, el 29 de setiembre del 2009, a las 17:48 horas GMT, generado por un terremoto de magnitud $8.3 \mathrm{M}_{\mathrm{w}}$. Durante los dos días posteriores al evento, las personas presentes en la Bahía Wafer observaron anomalías en las mareas, puesto que el nivel del mar bajaba y subía más rápido de lo normal $(\mathrm{O}$. Lizano, com. verbal 2012).

Recientemente, luego del terremoto de Japón del 11 de marzo 2011, cuya magnitud fue $9.0 \mathrm{M}_{\mathrm{w}}$, fue emitida una alerta de tsunami por el Centro de Investigación Científica y Educación Superior de Ensenada, México, con posibles olas de cerca de un metro (Ortiz 2011). En efecto, durante la noche de ese día fue reportado por los funcionarios del MINAET en la Isla del Coco, el efecto del tsunami en donde el nivel del agua invadió el piso inferior del centro de voluntarios en la Bahía Wafer, arrastró los botes hacia el interior de la bahía e inundó el sitio del geófono o sensor de la estación sismológica instalado en esa bahía.

Se dispone también sobre un posible paleo-tsunami descrito en Lockwood y Benumof (2000) y que afectara Bahía Wafer, pero se carece de un fechamiento.

Las fuentes sísmicas originadas por la interacción de placas tectónicas (e.g. zona de subducción) en América Central y Sudamérica, e incluso las fuentes más lejanas aún, como la subducción en Japón, podrían, dependiendo de la fuente, producir algún otro tsunami que afecte la Isla del Coco, por lo que es conveniente proteger las instalaciones en las partes planas de las bahías Chatham y Wafer. Como se ve, aunque los tsunamis no han ocasionado daños mayores y por el momento a los pocos pobladores en el período histórico, no se excluye la posibilidad de que en un futuro si lo hagan, dado que claramente la isla se encuentra en el camino de los tsunamis provenientes de Suramérica, Asia y América Central.

Por otro lado, tal y como fue discutido en el apartado anterior, también hay registros de sismicidad con eventos de hasta $5.8 \mathrm{M}_{\mathrm{w}}$. Si ocurriese un evento sísmico de este tipo cercano a la Isla del Coco, las pendientes elevadas de las laderas de la isla sobre y bajo el nivel del mar, la hace propensa a generación de deslizamientos subaéreos y submarinos, que podrían también y a su vez, generar tsunamis.

Sismicidad y fallas activas: Las fuentes sísmicas locales principales que podrían incidir generando aceleraciones sísmicas importantes en la Isla del Coco son: 1) la zonas de interacción por subducción, entre las placas del Coco, Caribe y Nazca, y 2) las zonas de fallas transcurrentes con rumbo N-S, como por ejemplo la Zona de Fractura de Panamá (ZFP) y 3) fallas locales (Figs. 1, 4 y 9). La primera podría generar magnitudes máximas de $7.8 \mathrm{M}_{\mathrm{w}}$, mientras que la ZFP de alrededor de $7.0 \mathrm{M}_{\mathrm{w}}$, 
pero, por la distancia considerable a la que se encuentran, las intensidades podrían no superar a IV (MM). Se tiene, recientemente, el caso del terremoto de El Salvador del 13/01/2001, 7.6 $\mathrm{M}_{\mathrm{w}}$ que generó intensidad de III MM en la Isla del Coco (Rojas 2001).

Tal y como se indicó previamente, la tercera fuente sísmica corresponde con la sismicidad en los alrededores del área de la Isla del Coco, que es muy baja y recientemente se han registrado dos sismos con magnitudes 5.7-5.8 $\mathrm{M}_{\mathrm{w}}$ localizado a unos $100-300 \mathrm{~km}$ de la Isla del Coco. Más estudios son necesarios para evaluar mejor las condiciones sismo-tectónicas y de amenaza sísmica local, pero por ahora se puede postular un sismo con magnitud $6.0 \mathrm{M}_{\mathrm{w}}$ en algún punto dentro de un radio de $200 \mathrm{~km}$.

\section{Inestabilidad de laderas, licuefacción} y erosión: La inestabilidad de las laderas, ya sea mediante la generación de deslizamientos regolíticos y caída de bloques, y aunque menos frecuentemente de tipo rotacional, es una de las amenazas para la infraestructura existente, por lo que deben de evaluarse de manera cuantitativa y precisa. Esto se justifica, en particular, debido a las laderas con pendientes fuertes, al ser un terreno volcánico bajo un régimen de precipitación pluvial intenso. Bergoeing (1994 en Bergoeing 1998) cartografió varios deslizamientos en la isla, que deben de comprobar y evaluar dentro del contexto de la seguridad de los habitantes y de la infraestructura. Tal y como se mencionó previamente, Rojas (2003) observó deslizamientos de rocas y tierra en las partes montañosas de la Isla del Coco, licuefacción en las playas y rajaduras, asociadas con el sismo del 12 de agosto de 1972.

\section{AGRADECIMIENTOS}

Al Sr. Fernando Quirós, Director del Área de Conservación Marina Isla del Coco, por su apoyo al proyecto de investigación en el Parque Nacional Isla del Coco, que nos ha permitido instalar equipo sismológico permanente. A Jorge Cortés por invitarnos a contribuir con el presente trabajo y realizar una primera revisión con comentarios valiosos. Dos lectores anónimos mejoraron substancialmente el contenido y redacción del presente trabajo. Alberto Vargas aportó información igualmente interesante y el oceanógrafo Omar Lizano amablemente nos cedió sus figuras batimétricas tridimensionales para interpretarlas y usarlas, que enriquecieron el contenido del presente trabajo. La Universidad de Kiel, junto con su instituto de investigaciones GEOMAR, y la Universidad de Costa Rica, permitieron la logística de poder visitar y estudiar la Isla del Coco. A Nury Morales, quien ha colaborado recientemente en la revisión de información sismológica de la estación sísmica de Isla del Coco, así mismo a los compañeros del Laboratorio de Sismología de UCR, en particular Magda Taylor y Carlos Redondo, quienes colaboraron en el procesado de información. A Luis Fernando Brenes de la $\mathrm{RSN}$, quien ha sido persona clave en la instalación y calibración del equipo sismológico que está operando en la Isla del Coco. Alberto Vargas, Allan Carrillo y Ana E. Vega colaboraron con las figuras. El presente trabajo es una contribución al proyecto de Fortalecimiento de la investigación en Estratigrafía y Tectónica, 830-B0-242, del Centro de Investigaciones Geológicas de la Universidad de Costa Rica.

\section{RESUMEN}

La Isla del Coco es la única isla oceánica y el único afloramiento subaéreo de la Cordillera Volcánica del Coco, el rasgo geográfico y geológico más extenso en aguas territoriales costarricenses. Desde el punto de vista geológico, está conformada por rocas volcánicas, predominantemente coladas de lavas basálticas y traquíticas en menor cantidad, con rocas piroclásticas y epiclásticas subordinadas. Posee suelos, coluvios y depósitos de playas (arenas y cantos) superficiales; su topografía es muy variable pero predomina el relieve quebrado y rugoso. La Isla del Coco es la parte emergida de un volcán submarino de evolución compleja, desarrollado a partir y durante el Pleistoceno Inferior (entre 2.2 y 1.5 millones de años, Ma), producto de una anomalía térmica en el manto a través de varias fisuras, que originaron varios alineamientos de volcanes submarinos. La Isla del Coco se encuentra en un estadio de erosión activo, y sus arcos y plataformas sumergidas (90-110m y $183 \mathrm{~m})$ son probablemente el producto de una erosión subaérea durante las dos últimas máximas glaciaciones, combinados quizás con la subsidencia debida al enfriamiento del 
escudo volcánico y de la corteza oceánica. Al ser la isla geológicamente joven, posee importantes implicaciones para la comprensión de la evolución y el endemismo de su biodiversidad. Las amenazas en la geodinámica principales identificadas son los deslizamientos, los tsunamis y, en menor grado, la sismicidad, poco frecuente y con magnitudes moderadas ( $\leq 5.8 \mathrm{M}_{\mathrm{w}}$ hasta la fecha) dentro de un radio de alrededor de $300 \mathrm{~km}$, predominantemente asociada con fallas dextrales de rumbo N-S. Los pocos datos obtenidos hasta el momento indican que hay un cierto grado de actividad sísmica en los alrededores de la Isla del Coco, relacionados con las fallas locales. Algunos pequeños tsunamis históricos y prehistóricos han afectado a la Isla del Coco y los sismos así como la precipitación pluvial elevada han generado deslizamientos. La licuefacción está restringida a las dos playas arenosas (bahías Chatham y Wafer).

Palabras clave: Costa Rica, Isla del Coco, Cordillera Volcánica del Coco, geología, maremotos, sismotectónica, peligros geológicos.

\section{REFERENCIAS}

Adamek, S., C. Frohlich \& W. Pennington. 1988. Seismicity of the Caribbean-Nazca boundary: Constraints on microplate tectonics of the Panama region. J. Geophys. Res. 93 (B3): 2053-2075.

Alvarado, G.E. 1984. Aspectos Petrológicos-Geológicos de los Volcanes y Unidades Lávicas del Cenozoico Superior de Costa Rica. Tesis Licenciatura, Univ. Costa Rica, San Pedro, San José, Costa Rica.

Alvarado, G.E. 2000. Los volcanes de Costa Rica: Su geología, historia y riqueza natural. EUNED, San José, Costa Rica.

Alvarado, G.E. \& P.B. Gans. 2012. Síntesis geocronológica del magmatismo, metamorfismo y metalogenia de Costa Rica, América Central. Rev. Geol. Amér. Central 46: 7-122.

Arias, R. 1990. Isla del Coco, Historia y Leyenda. Tesis Licenciatura, Univ. Costa Rica, San Pedro, San José, Costa Rica.

Bellon, H., R. Sáenz \& J. Tournon. 1983. K/Ar radiometric ages of lavas from Cocos Island (eastern Pacific). Mar. Geol. 54: M17-M23.

Bergoeing, J.P. 1998. Geomorfología de Costa Rica. Inst. Geogr. Nacional, San José, Costa Rica.

Burke, K.C. \& J.T. Wilson. 1976. Hot Spots on the Earth's Surface. Scient. Amer., August: 46-57.

Castillo, P., B. Batiza, D. Vanko, E. Malavassi, J. Barquero \& E. Fernández. 1988. Anomalously young volcanoes on old-spot traces: geology and petrology of Cocos Island. Geol. Soc. Amer. Bull. 100: 1400-1414.
Chubb, L.J. 1933. Geology of Galápagos, Cocos and Eastern Islands with petrology of Galápagos. Bernice P. Bishop Museum Bull. 110: 1-67.

Cortés, J. 2007. Coastal morphology and coral reefs. In J. Bundschuh \& G.E. Alvarado (eds.). Central America: Geology, Resources and Hazards. Taylor \& Francis, Londres 1: 185-200.

Cortés, J. 2008. Historia de la investigación marina de la Isla del Coco, Costa Rica. Rev. Biol. Trop. 56 (Supl. 2): 1-18.

Dalrymple, G. \& A. Cox. 1968. Paleomagnetism, Potassium-Argon ages and petrology of some volcanic rocks. Nature 217: 323-326.

Fairbanks, R.G. 1989. A 17,0000-year glacio-eustactic sea level record: influence of glacial melting rates on the Younger Dryas event and deep-ocean circulation. Nature 342: 637-642.

Fleming, K., P. Johnston, D. Zwartz, Y. Yokoyama, J. Lambeck \& J. Chappell. 1998. Refining the eustatic sea-level curve since the Last Glacial Maximum using far- and intermediate-field sites. Earth Planet. Sci. Lett. 163: 327-342.

Gazel, E., K. Hoernle, M.J. Carr, C. Herzberg, I. Saginor, P. Van den Bogaard, F. Hauff, M. Feigenson \& C. Swisher III. 2011. Plume-subduction interaction in southern Central America: Mantle upwelling and slab melting. Lithos 121: 117-134.

Harpp, K.S., V.D. Wanless, R.H. Otto, K. Hoernle \& R. Werner. 2005. The Cocos and Carnegie aseismic ridges: a trace element record of long-term plumespreading center interaction. J. Petrol. 46: 109-133.

Hey, R. 1977. Tectonic evolution of the Cocos-Nazca Spreading. Geol. Soc. Amer. Bull. 88: 1404-1420.

Hey, R., G.L. Johnson \& A. Lowrie. 1977. Recent plate motions in the Galápagos area. Bull. Geol. Soc. Amer. 88: 1385-1403.

Lizano, O.G., 2001. Batimetría de la plataforma insular alrededor de la Isla del Coco, Costa Rica. Rev. Biol. Trop. 49 (Supl. 2): 163-170.

Lizano, O.G. 2012. Rasgos batimétricos de la Isla del Coco y sus montañas submarinas vecinas. Rev. Biol. Trop. 60 (Suppl. 3): 43-51.

Lockwood, J.P. \& B.T. Benumof. 2000. Investigaciones de las cuevas marinas de la isla del Coco. Datos de campo. Inf. Geohazards Consult. Internat., Puffin Invest. Co. Inc., P.O. Box 479, Volcano Hawaii 96785, EE.UU., Trad. español: Z. Jurado.

Malavassi, E. 1982.Visita al Parque Nacional Isla del Coco. Rev. Geográf. Amér. Central 15-16: 211-216.

Meschede, M., U. Barckhausen \& H.-U. Worm. 2000. Extinct spreading on the Cocos Ridge. Terra Nova 10: 211-216. 
Muhs, D., J.F. Wehmiller, K.R. Simmons \& L.L. York. 2003. Quaternary sea-level history of the United States. Develop. Quatern. Sci. 1: 147-183.

O’Connor, J.M., P. Stoffers, J.R. Wijbrans \& T.J. Worthington. 2007. Migration of widespread long-lived volcanism across the Galápagos Volcanic Province: Evidence for a broad melting anomaly? Earth Planet. Sci. Lett. 263: 339-354.

Ortiz, M. 2011. Observaciones del tsunami de Japón del 11 de marzo del 2011. Bol. CISESI, Ensenada, México. 2 p.

Rabineau, M., S. Berné, J.-L. Olivet, D. Aslanian, F. Guillocehau \& P. Joseph. 2006. Paleo sea levels reconsidered from direct observation of paleoshoreline position during Glacial Maxima (for the last 500,000 yr). Earth Planet. Sci. Lett. 252: 119-137.

Rojas, W. 2000. Informe Geológico para el Proyecto Hidroeléctrico Río Genio, Isla del Coco. Resumen Ejecutivo Preliminar de la visita al sitio. Red Sismológica Nacional UCR-ICE, San José, Costa Rica.

Rojas, W. 2001. Informe del monitoreo sismológico en la Isla del Coco, Costa Rica. Reporte Técnico No01,
Proyecto 113-A1-906, Vice-rectoría de Investigación, Univ. Costa Rica, San José, Costa Rica.

Rojas, W. 2003. Temblor de la Isla del Coco del 12 de agosto de 1972 a las 07:15 AM. Resumen descriptivo para Memorias del Mini-taller Anual de RSN del 28 de octubre 2003. Escuela Centroamericana de Geología, Univ. Costa Rica, San Pedro Montes de Oca, Costa Rica.

Rojas, W. 2009. Sismo registrado en la Serranía Oceánica de Coco. Inf. $N^{\circ}$ III para el Proyecto Monitoreo Sísmico de la Isla del Coco, bajo la dirección del Geól. W. Rojas, Sección de Sismología de la UCR, agosto 2009, San Jose, Costa Rica, 5 págs.

Werner, R., K. Hoernle, U. Barckhausen \& F. Hauff. 2003. Geodynamic evolution of the Galápagos hot spot system (Central East Pacific) over the past 20 m.y.: Constraints from morphology, geochemistry, and magnetic anomalies. Geochem. Geophys. Geosyst. 4 (12), 1108, doi: 10.1029/2003GC000576.

Weston, C. 1992. La Isla del Coco/Cocos Island. Trejos Hnos. Sucesores S.A., San José, Costa Rica. 